\title{
The ClaudicatioNet concept: design of a national integrated care network providing active and healthy aging for patients with intermittent claudication
}

\author{
This article was published in the following Dove Press journal: \\ Vascular Health and Risk Management \\ 23 August 2012 \\ Number of times this article has been viewed
}

\author{
Gert-Jan Lauret ${ }^{1,2}$ \\ Harm JH Gijsbers ${ }^{3}$ \\ Erik JM Hendriks² \\ Marie-Louise Bartelink ${ }^{4}$ \\ Rob A de Bie ${ }^{2}$ \\ Joep AW Teijink ${ }^{1,2}$ \\ On behalf of the \\ ClaudicatioNet Study \\ Group members \\ 'Department of Vascular Surgery, \\ Catharina Hospital, Eindhoven, \\ The Netherlands; ${ }^{2}$ Caphri \\ Research Institute, Department of \\ Epidemiology, Maastricht University, \\ Maastricht, The Netherlands; ${ }^{3}$ Dutch \\ Society for Heart, Vascular and \\ Lung Physiotherapy, Meijerslaan PG \\ Heemstede, The Netherlands; ${ }^{4}$ Julius \\ Center Health Sciences and Primary \\ Care, University Medical Center \\ Utrecht, Utrecht, The Netherlands
}

Correspondence: JAW Teijink

Catharina Hospital, PO Box 1350, 5602

ZA, Eindhoven, The Netherlands

$\mathrm{Tel}+3 \mathrm{I} 402397155$

Fax +3I 402443370

Email joep.teijink@cze.nl
Introduction: Intermittent claudication (IC) is a manifestation of peripheral arterial occlusive disease (PAOD). Besides cardiovascular risk management, supervised exercise therapy (SET) should be offered to all patients with IC. Outdated guidelines, an insufficient number of specialized physiotherapists (PTs), lack of awareness of the importance of SET by referring physicians, and misguided financial incentives all seriously impede the availability of a structured SET program in The Netherlands.

Description of care practice: By initiating regional care networks, ClaudicatioNet aims to improve the quality of care for patients with IC. Based on the chronic care model as a conceptual framework, these networks should enhance the access, continuity, and (cost) efficiency of the health care system. With the aid of a national database, health care professionals will be able to benchmark patient results while ClaudicatioNet will be able to monitor quality of care by way of functional and patient reported outcome measures.

Discussion: The success of ClaudicatioNet is dependent on several factors. Vascular surgeons, general practitioners and coordinating central caregivers will need to team up and work in close collaboration with specialized PTs. A substantial task in the upcoming years will be to monitor the quality, volume, and distribution of ClaudicatioNet PTs. Finally, misguided financial incentives within the Dutch health care system need to be tackled.

Conclusion: With ClaudicatioNet, integrated care pathways are likely to improve in the upcoming years. This should result in the achievement of optimal quality of care for all patients with IC.

Keywords: intermittent claudication, supervised exercise therapy, integrated care network, chronic care model, active healthy aging

\section{Introduction}

Peripheral arterial occlusive disease (PAOD) is an expression of systemic atherosclerosis. Plaque formation causes progressive narrowing and hardening of the arteries in the legs. The manifestation of PAOD is variable, with some patients being asymptomatic and others developing tissue loss that ultimately necessitates amputation of the affected limb. ${ }^{1}$ The prevalence of PAOD is estimated to be $1.6 \%$ to $4.5 \%$ in the general population and as high as $19.1 \%$ in the Dutch population aged 55 years and older. ${ }^{2-6}$

Intermittent claudication (IC), the mildest symptomatic manifestation of PAOD, is defined as pain in the muscles of the leg during exercise that is relieved by a short 
period of rest. It is reported in $4.5 \%$ to $32.5 \%$ of all patients with PAOD. ${ }^{2,3,5}$ A 5-year mortality rate of $19.2 \%$ is described for IC, of which $70 \%$ is due to cardiovascular causes. Nonfatal cardiovascular events (eg, myocardial infarction, stroke) are found in $29 \%$ of patients with IC within 5 years of follow-up. ${ }^{7}$ The prevalence of cerebrovascular disease in patients with IC is about $25 \%-50 \%{ }^{8}$

Numerous consensus documents, including the American College of Cardiology/American Heart Association and the Trans-Atlantic Inter-Society Consensus on Management of Peripheral Arterial Disease guidelines on PAOD, provide recommendations for diagnosis and management of patients with PAOD. ${ }^{1,9}$ These guidelines identify patients with IC as a high-risk population who require intensive risk factor modification. Blood pressure levels, glucose, and cholesterol metabolism should all be optimized. Attention should be paid to smoking cessation since smoking is considered the most important modifiable vascular risk factor. Antiplatelet therapy and the use of a statin is indicated for all IC patients to reduce the risk of cardiovascular events. ${ }^{10,11}$

The primary symptomatic treatment for IC is exercise therapy, which was first suggested by Erb in $1898 .{ }^{12,13}$ In a Cochrane review of systematic reviews, Watson et al described an overall improvement in maximal walking time with a mean difference of 5.12 minutes (95\% confidence interval 4.51-5.72) in favor of exercise therapy compared with usual care or placebo. ${ }^{14}$ Exercise therapy consisted of all sorts of exercise prescriptions, including walking advice and unsupervised exercise regimes. Further benefit of exercise therapy was seen in the reduction of cardiovascular risk factors including hypercholesterolemia, hypertension, and diabetes mellitus. ${ }^{15}$ Given its clear benefits, the importance of exercise therapy is highlighted in contemporary international guidelines. ${ }^{1,9}$

In daily practice, lack of specific individual guidance and the absence of uniform supervision appear to be important barriers to the initiation and continuation of exercise therapy. ${ }^{16}$ For this reason, exercise programs under supervision of a physiotherapist (PT) are considered beneficial. A Cochrane review by Bendermacher et al showed that supervised exercise therapy (SET) was superior to an unsupervised exercise program. The maximum walking distance increased by an additional 150 meters in patients treated with SET compared to those involved in unsupervised exercise programs. ${ }^{17}$

In a cohort study, community-based SET appeared to be as effective as hospital-based SET. ${ }^{18}$ Compared to outpatient hospital-based SET, community-based SET has the advantage of providing a larger capacity of care, and in most cases, being feasibly close to the patient's home environment with reduced transport costs. With this body of evidence, it is clear that SET should be offered to all patients with IC.

\section{Problem statement}

In The Netherlands, there are several reasons why a structured SET program is not offered to all patients with IC.

\section{Outdated guidelines for referring physicians}

In The Netherlands, the diagnosis of IC is determined by a general practitioner or a vascular surgeon. In all cases, the general practitioner (GP) has to initiate cardiovascular risk management according to the 2011 Dutch multidisciplinary guideline "Cardiovascular Risk Management."19 Both general practitioners and vascular surgeons are expected to start conservative symptomatic treatment for patients with IC, according to contemporary international guidelines for PAOD. ${ }^{1,9}$ However, the guidelines of the Dutch Association of General Practitioners and Dutch Society for Vascular Surgery are in an urgent need of updating, since SET is not advocated as initial treatment for patients with IC. ${ }^{20,21}$

\section{Outdated arguments for not referring a patient to a SET program}

A quarter of new patients with IC seen by a vascular surgeon do not receive SET, as recently described in a national survey. ${ }^{22}$ The referral rate of GPs is unknown, although it is most probably low, given the small impact IC has on the general practice of a GP.

Vascular surgeons who do refer to SET (75.4\%) mentioned arguments why not to refer patients to SET in certain cases, including: existing significant cardiopulmonary comorbidity; an aortoiliac stenosis or occlusion causing IC; and limited availability of sufficiently specialized PTs. ${ }^{22}$ Nevertheless, only the limited availability of PTs seems to be a valid argument. According to current literature, the other arguments mentioned appear to be outdated. ${ }^{22}$

Furthermore, in case of severe or invalidating IC, invasive vascular interventions are often performed without first awaiting the effects of a structured SET program. If a better infrastructure of specialized PTs existed, more patients would be able to receive SET from the onset of their condition.

\section{Referred to whom?}

Once indications and referrals for SET are properly established, the next question is: To whom should 
the patient be referred? The more than 22,000 PTs in The Netherlands should make it possible to provide SET according to the Royal Dutch Society for Physical Therapy guideline. ${ }^{23}$ However, the majority of these PTs are not adequately schooled in providing SET and do not have sufficient experience to provide this form of therapy. Patients with IC suffer from a variety of comorbidities and modifiable lifestyle factors, potentially generating suboptimal results if these aspects are not addressed appropriately. When adequately trained, PTs should ideally be able to perform individual training, recognize alarm symptoms (so-called red and yellow flags) and even provide lifestyle counseling or monitor medication adherence. Volume criteria could have an influence on patient outcomes, since in general, more experience leads to better results. In order to achieve these better patient outcomes, differentiation in the field of physical therapy is needed.

\section{Misguided financial incentives}

Not least of the problems is the fact that the Dutch health care system does not stimulate use of conservative treatment for patients with IC, while invasive vascular interventions are fully compensated. The Dutch government determines the scope of coverage for basic health care and health insurers are obligated to accept people for this insurance without any selection. For additional coverage to the basic health insurance package, voluntary additional health care insurance can be acquired. Health insurers can determine the content and prices for their additional packages and can refuse acceptance for additional coverage for high-risk patients.

In this system, services provided by the GP or vascular surgeon, such as cardiovascular risk management or invasive vascular interventions, are fully compensated by basic health care insurance. However, for physiotherapy, the first 20 treatment sessions of SET (for IC) are not covered by basic health care insurance and have to be paid by the patient himself or by additional insurance (since January 1, 2012). All further treatment sessions, for a total of 1 year, are covered by basic health care insurance. Therefore, in some cases, patients with IC have a financially driven interest to be treated by vascular surgeons who deliver invasive vascular interventions (for instance angioplasty or bypass surgery), in disregard of the associated risk of morbidity $(<0.5 \%-10 \%)$ and even mortality ( $2 \%-3 \%$ for bypass surgery). ${ }^{12}$

To tackle some of the aforementioned shortcomings, the ClaudicatioNet concept was developed and launched in The Netherlands in 2011.

\section{Description of care intervention: ClaudicatioNet}

The goal of the ClaudicatioNet program is to improve the quality of care for patients with IC by creating connectivity and collaboration between the various players (including the patient) within the Dutch health care system. In general, by initiating regional care networks, ClaudicatioNet aims to enhance the access, continuity and (cost) efficiency of the health care system. Furthermore, it aims to improve patient responsibility, patient satisfaction, and quality of life for all patients with PAOD in The Netherlands.

\section{Initiation of the ClaudicatioNet concept}

The EXITPAD trial provided level Ib evidence to support supervision in conjunction with exercise therapy for patients with IC. ${ }^{24}$ The concept of ClaudicatioNet is based on the methods and results of this trial. In particular, many logistical efforts to make this trial possible provided useful knowledge for the initiation of the ClaudicatioNet concept. For the implementation period, an administration and monitoring office became available after an initiation grant from the Innovation Fund of the Joint Dutch Healthcare Insurers. During the implementation, ClaudicatioNet shall initiate a cost-effectiveness analysis, which should provide the basis for acquiring structural financial support.

ClaudicatioNet started in 2011 to initiate regional care networks between specially trained PTs, central caregivers, and vascular surgeons. After initiation of a network, general practitioners are able to use the network's infrastructure. In regional networks, transparent, synergistic, and multidisciplinary care has to be provided, based on the guidelines of cardiovascular risk management, SET, and the Innovative Care for Chronic Conditions framework of the World Health Organization. ${ }^{1,9,19,25}$ In addition to these evidence-based guidelines, the Dutch Health Care Inspectorate has developed (on behalf of the Ministry of Health, Welfare, and Sport) a set of mandatory key performance indicators. ${ }^{26}$ To meet these indicators, hospitals need to have a network of trained PTs capable of providing SET for patients with IC by 2012.

The goal of ClaudicatioNet is to initiate the establishment of regional networks throughout The Netherlands in a 3-year time period (January 2011-December 2013). Since every network requires a 3- to 4-year period to expand to the desired level, full nationwide implementation should be achieved by 2016. The Dutch Society for Vascular Surgery, the Royal Dutch Society for Physical Therapy, and the Dutch Patient Association for Heart and Vascular Diseases (De Hart-en Vaatgroep) currently support ClaudicatioNet. 
With these partners, broad backing is in place to successfully implement this integrated care concept.

\section{Creation of care chains}

Ideally, the care for PAOD patients is initiated by general practitioners and provided by health care professionals connected within horizontal primary care chains. In The Netherlands, there are successfully operating and wellequipped primary care chains for diabetes and COPD that have proven to be able to deliver care to conform to national guidelines and care standards. However, at this moment, most GPs do not participate in structured programs focusing on vascular risk management and do not take a leading or supervising role in the management of IC. There is an urgent need to solve this problem, since a well-organized SET program is stated in all contemporary guidelines and is listed as a key performance indicator by governmental bodies. To overcome the present care gap for patients with IC, a feasible and realistic solution had to be found. At this moment, most patients are referred for SET by the 163 certified and practicing vascular surgeons in The Netherlands. The majority of these surgeons are motivated to contribute to the establishment of the ClaudicatioNet concept.

Therefore, regional networks were chosen for establishment amongst vascular surgeons, central caregivers, and PTs. After initiation, GPs will be able to use the network's infrastructure. Further integration with three Dutch primary care health clusters (De Ondernemende Huisarts [DOH], PoZoB, Stichting Gezondheidscentra Eindhoven [SGE]) is being explored in a region of the country where there is sufficient experience in setting up health care chains.

Both referring physicians and PTs will benefit from participation in ClaudicatioNet. For referring physicians, an infrastructure for care delivery with the use of specialized PTs becomes available. By only referring patients to PTs connected to ClaudicatioNet, vascular surgeons, general practitioners, and health care insurers are guaranteed transparent and standardized high quality treatment for each patient. For vascular surgeons, a regional network is enrolled by ClaudicatioNet, which complies with the mandatory key performance indicator established by the Dutch Health Care Inspectorate.

For PTs, ClaudicatioNet will provide a trajectory of specialization in PAOD. This trajectory could be complementary to existing PT specializations in the field of chronic illness or cardiopulmonary rehabilitation. Because of the growing need for differentiation in the field of physical therapy, participation will be a strategic choice for each individual
PT or group practice. Furthermore, it is expected that the number of referrals per PT will increase significantly, since only a proportion of all available PTs will participate in ClaudicatioNet and only these PTs will receive referrals. However, each PT has to make an economic trade-off between the potential profit and required investments derived from the mandatory participation criteria. How many referrals will lead to an acceptable profit giving the necessary investments is yet uncertain. The answer pertaining to the viability of the business model of the program for primary care PTs is important with regard to the incentive to prolong future participation. Supply and demand of SET will evolve and reach equilibrium over time.

\section{Improving integrated care pathways using the chronic care model}

The structure of and working method for ClaudicatioNet is based on the internationally (World Health Organization) accepted chronic care model that provides an evidence-based, conceptual framework to improve the functional and clinical outcomes for people with chronic illness. The chronic care model describes interacting system components, which are important for providing good chronic illness care: selfmanagement support, delivery system design, decision support, and clinical information systems (Figure 1). ${ }^{27}$ The model also includes the organization of the health care system and other conditional factors, such as resources and policies.

ClaudicatioNet bridges the gap between the various health care professionals (eg, GPs and their practice assistants, vascular surgeons, specialized nurses in vascular surgery, and PTs). Together they are able to provide the best standards of practice. Patients play a pivotal role in the care given. Specific information, treatment goals, and obtained results need to be

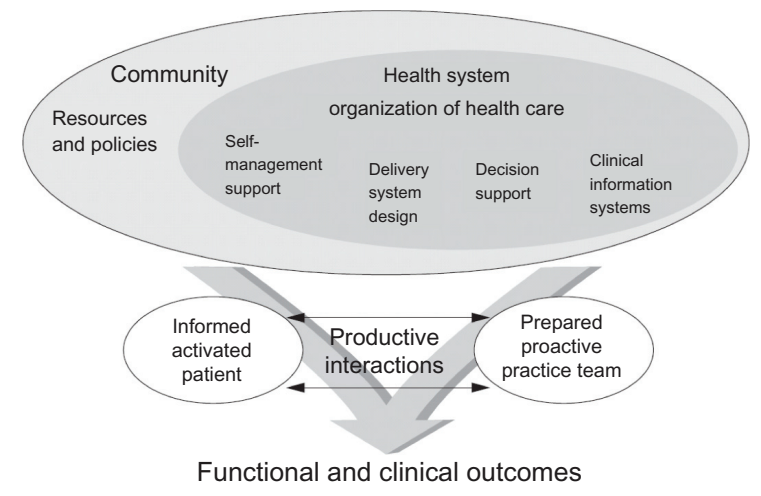

Figure I The chronic care model.

Adapted by permission from BMJ Publishing Group Limited. Improving the quality of health care for chronic conditions, Epping-Jordan JE, Pruitt SD, Bengoa R, Wagner $\mathrm{EH}$, 13, 299-305, (c) 2004. 
communicated to the patient. Many more treatment goals (lifestyle counseling, monitoring of medication adherence) should ideally be reiterated and explained by all involved caregivers. However, the risk of health related information fatigue must be avoided. All of these elements indicate the need for an integrated care approach. The chronic care model is used as a framework to improve the integrated care pathways and the quality of care provided by all health care professionals (Figure 2).

\section{Patients}

Patients are centrally placed in the care structure of the ClaudicatioNet concept, in which patient self-management is essential for optimal patient outcomes. Health care professionals need to support and facilitate self-management and patient empowerment. In general, patients with IC have a low level of physical activity, and in the majority of cases, favor an unhealthy lifestyle (smoking, poor diet, lack of movement).

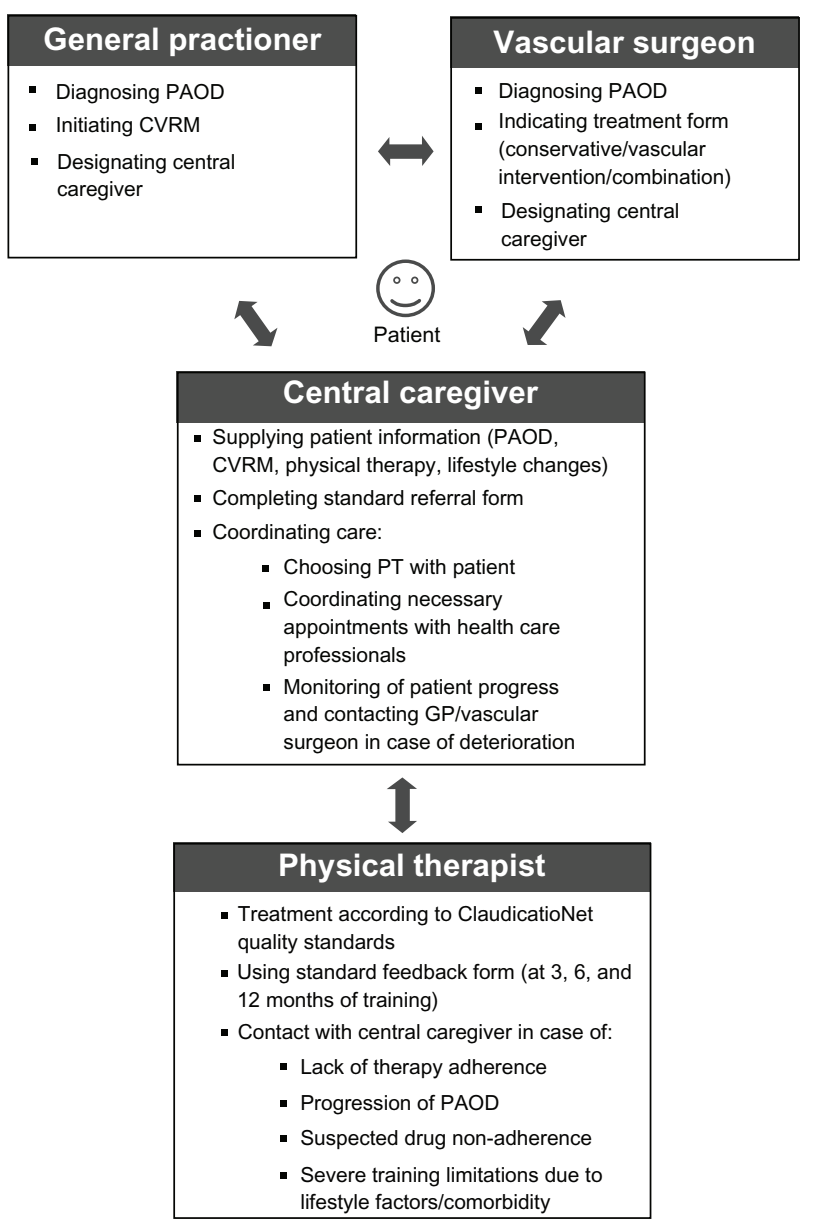

Figure 2 Integrated care pathways.

Abbreviations: CVRM, cardiovascular risk management; GP, general practitioner; PAOD, peripheral arterial occlusive disease; PT, physiotherapist.
An essential part of a successful SET program is self-initiated exercise between supervised training sessions.

In addition to the provided services of the involved health care professionals, ClaudicatioNet will provide supporting patient information through an interactive patient web portal. With the aid of this web portal, patients are directed to background information regarding their disease, SET, and/or lifestyle influences. Patients will be able to find a specialized ClaudicatioNet PT in the online care finder and after initiation of SET, patients will have the ability to monitor their own progress (based on individual data within the ClaudicatioNet database) in a user-friendly dashboard.

Automatic reminders and the use of the interactive mobile application "WalkMate" should increase patient self-management adherence. With this application, it will be possible for patients to find, meet, and train with other patients.

To evaluate the treatment provided by all the health care professionals, patients are asked to provide feedback on the number of treatment sessions, treatment protocol, facilities, and expertise of the individual health care professionals. Special attention will be paid to whether a patient receives training by a specialized PT.

\section{General practitioners and vascular surgeons}

General practitioners and vascular surgeons are the first caregivers to confront a patient with a diagnosis of IC, and thus, have the responsibility to diagnose compounding cardiovascular risk factors and attributing lifestyle factors. Ideally, GP's diagnose IC and initiate cardiovascular risk management while vascular surgeons determine if vascular intervention is necessary. The guideline from the Dutch General Practitioners Society leaves the option for referral to a vascular surgeon in case of doubt or the lack of available resources to perform an ABI (ankle-brachial index). In these cases, a vascular surgeon initiates or advises first-line treatment. After the diagnosis is made and the treatment is indicated, each patient should be individually designated to a central caregiver who will coordinate the patient's essential care. Ideally, this takes place in the primary care setting.

ClaudicatioNet necessitates that vascular surgeons only refer patients to a specialized ClaudicatioNet PT. Patients will be asked to provide feedback regarding the quality of care provided by the health care professional. Also, the number and origin of referrals will be monitored in the national ClaudicatioNet database and can, with the cooperation of health care insurers, be compared with the total number of patients with IC. 


\section{Central caregiver}

Central caregivers (GP practice assistants or specialized vascular surgery nurses) play a major role in providing patienttailored management and coordinating the care provided by all involved caregivers. In an ongoing relationship with the patient, central caregivers provide integrated information regarding the patient's condition, prognosis, influencing factors, and treatment progress. Patients need to be supported in order to improve the management of their condition. Preferably, it is the patient and his or her central caregiver who select a ClaudicatioNet PT. The central caregiver is responsible for the content and the process of the care given. He or she is financially supported by the GP's practice or vascular surgery department in order to provide structure and follow-up according to the second component of the chronic care model.

In addition to these tasks, central caregivers provide lifestyle advice, monitor therapy adherence, and initiate contact with the GP or vascular surgeon in case of deterioration of the patient's condition. Therefore, a central caregiver needs to work in close collaboration with all participating PTs in the regional network. In order to improve the system design, ClaudicatioNet has developed standardized SET referral forms and patient leaflets with information regarding the interactive patient web portal. Central caregivers will be able to monitor the progress of their patients with a user-friendly web-based dashboard connected to the ClaudicatioNet database.

\section{Physiotherapists}

PTs participating in ClaudicatioNet perform standardized and evidence-based SET, perform lifestyle interventions (eg, smoking cessation, dietary advice) and regularly (2-4 times a year) assess medication adherence - all in close collaboration with the central caregiver. Prior to participating in a regional ClaudicatioNet network, PTs must meet the set inclusion criteria (Table 1).

Prior to launching a regional network, a certified schooling program on "Intermittent Claudication," is provided by

Table I Inclusion criteria for aspiring PTs

- Completed the course "Intermittent Claudication," certified by the Royal Dutch Society for Physical Therapy.

- Owns or works at a well-equipped practice with a treadmill (with inclinometer), bicycle ergometer, reanimation protocol, automatic electronic defibrillator, and internet connection, and which has an established program of yearly equipment maintenance.

- Broadly oriented PT who recognizes, reports, and acts on other limitations (like COPD, arthrosis, gait) that influence the patient's progress.

Abbreviations: COPD, chronic obstructive pulmonary disease; PT, physiotherapist.
ClaudicatioNet for all aspiring PTs. In this program, special attention is paid to assessment of medication adherence and the standardized supervised exercise therapy protocol of the Royal Dutch Society for Physical Therapy. ${ }^{23}$

After acceptance, a PT is included in ClaudicatioNet's online care-finder, which ideally should lead to an increase in the number of referrals. In a 3-year, step-wise program, PTs need to comply with increasing quality standards to ensure continued participation and referrals (Table 2). One additional year can be spent if the requirements of any given step in the specialization process cannot be met. This results in a total requirement of 4 years to obtain full specialization.

In the process of specialization, all PTs should stimulate lifestyle changes (smoking cessation, weight loss, increasing physical activity) during the treatment process of each patient while central caregivers should provide lifestyle advice and monitor the effects of the combined efforts. Patients with cardiovascular disease often need to change multiple behaviors; therefore, it is important to assess which behavior is most important for the patient to change. Motivational interviewing (MI) is a client-centered, directive method for enhancing intrinsic motivation to behavior change by exploring and resolving ambivalence. ${ }^{28}$ It is a dynamic and interactive process where there is reciprocity between the patient and the counselor.

In a meta-analysis of 72 RCTs, MI effectively helped patients change their lifestyle and outperform traditional advice in approximately $80 \%$ of all studies. ${ }^{29}$ MI can be effective in brief encounters of only 15 minutes and more than one encounter increases the likelihood of an effect in behavior change. This effect was not related to the counselor's educational background, although it would be reasonable to speculate that training and experience could influence effectiveness. Given their frequent contact with patients (three times a week for at least 3 months), PTs are, in this concept, the ideal counselors to initiate a lifestyle intervention. For this reason, all participating ClaudicatioNet PTs are schooled with a certified 3-day Motivational Interviewing (MI) course. ClaudicatioNet will provide such a program and other existing MI courses will be evaluated and certified.

After meeting the final criteria, PTs must update their knowledge by attending the annual ClaudicatioNet congress once every 2 years and participating in lifelong learning activities through relevant schooling (15 dedicated study hours/year).

ClaudicatioNet provides an "ask the expert" module, if a PT is confronted with a complex situation in his or her daily practice. This module is part of the ClaudicatioNet 
Table 2 Participation criteria

\begin{tabular}{|c|c|c|}
\hline Step I & Step 2 & Step 3 \\
\hline $\begin{array}{l}\text { Standard care: delivers transparent care according } \\
\text { to protocol, provides feedback to vascular surgeon, } \\
\text { and has adequate patient administration. }\end{array}$ & $\begin{array}{l}\text { Practice visitation: complies with quality } \\
\text { indicators on transparency and quality of care, } \\
\text { organization of practice, portfolio, and patient } \\
\text { administration. }\end{array}$ & $\begin{array}{l}\text { Patient follow-up system: works } \\
\text { in the third year with a patient } \\
\text { follow-up system that supplies data to } \\
\text { the national ClaudicatioNet database. }\end{array}$ \\
\hline $\begin{array}{l}\text { Schooling: attends continuous medical education } \\
\text { on peripheral arterial disease or concomitant disease. } \\
\text { In total, I } 5 \text { credits should be obtained each year. } \\
\text { The ClaudicatioNet congress is mandatory every }\end{array}$ & $\begin{array}{l}\text { Schooling: attends continuous medical education } \\
\text { on peripheral arterial disease or concomitant disease. } \\
\text { In total, I } 5 \text { credits should be obtained each year. } \\
\text { The ClaudicatioNet congress is mandatory every }\end{array}$ & $\begin{array}{l}\text { Schooling: attends continuous } \\
\text { medical education on peripheral } \\
\text { arterial disease or concomitant disease. } \\
\text { In total, I } 5 \text { credits should be obtained }\end{array}$ \\
\hline 2 years. & 2 years. & $\begin{array}{l}\text { each year. The ClaudicatioNet } \\
\text { congress is mandatory every } 2 \text { years. }\end{array}$ \\
\hline $\begin{array}{l}\text { Progress: completes an electronic inquiry } \\
\text { of all results and number of patients. }\end{array}$ & $\begin{array}{l}\text { Portfolio: provides an updated personal portfolio } \\
\text { for web use (care-finder module). }\end{array}$ & $\begin{array}{l}\text { Course: completes the course } \\
\text { "Motivational Interviewing" and is } \\
\text { able to perform lifestyle intervention } \\
\text { for each patient. }\end{array}$ \\
\hline
\end{tabular}

website and facilitates discussion about treatment difficulties with an expert PT; this relates to the decision support component of the chronic care model. For efficiency in the delivery system design, ClaudicatioNet equips PTs with standard feedback forms. These forms provide essential information as inventoried in a national survey amongst vascular surgeons. ${ }^{22}$

The progress of individual PTs will be monitored, and if necessary, acted upon. Quality evaluation based on a clinical information system is possible once PTs supply data (eg, patient outcomes, number of treatment sessions, referral information) to the national ClaudicatioNet database. Recently, a set of evidence-based performance indicators has been developed by our research group (unpublished data). This data will be combined at regular intervals with measured feedback from patients (eg, the number and content of training sessions, treatment provision by appropriate (certified) caregivers, satisfaction, and perceived quality of care). With this data, ClaudicatioNet will be able to monitor and improve quality of care in the future. Furthermore, by combining outcome and cost parameters it will be possible to perform a cost-effectiveness analysis and evaluate the efficacy of ClaudicatioNet compared to usual care.

ClaudicatioNet promotes networking between health care professionals by organizing regional network meetings with PTs, case managers, GPs, and vascular surgeons. The goal of these meetings is to evaluate daily practice and exchange knowledge. ClaudicatioNet also organizes an annual congress focusing on the management of PAOD. As part of the congress, two parallel regional lunch programs - one specific for PTs and one aimed at case managers - are organized. This lunch program enables both groups to discuss regional organizational aspects (for instance, network meetings, regional schooling, or other activities) and the coordination of regional care (for instance, referral practice, quality of feedback).

\section{Discussion}

Once ClaudicatioNet is operating nationwide, more patients with symptomatic PAOD, if not all, will benefit from standardized SET. This will lead to a reduced need for vascular interventions (percutaneous angioplasties or peripheral bypass operations). Morbidity and mortality due to these prevented interventions will cease to exist, resulting in substantial improvement in the health of the PAOD population. Prevention of costly interventions will also lead to a reduction in overall health costs. The promotion of lifestyle activities by different caregivers as well as structured, supervised, and self-initiated health-stimulating exercise therapy will also have beneficial effects on the general health of patients. This, in turn, is likely to lead to reduced complications from existing comorbidities.

Health care insurers support this innovative concept and are willing to participate. A decline in the total number of vascular interventions has already been noted after the successful implementation of the first regional integrated care networks for IC. In the upcoming years, the number of patients admitted to ClaudicatioNet PTs will be compared to historical data and to the total number of vascular interventions. Patient outcomes will be gathered in the ClaudicatioNet database and compared to existing data. It is through these means that the success of ClaudicatioNet will be determined. In our opinion, the existence of a central caregiver as an easily accessible contact person within the first regional network has already improved patient communication and interaction between health care providers. 
Success of ClaudicatioNet is, however, dependent upon several factors. Vascular surgeons and GPs will need to refer patients with IC to PTs connected with ClaudicatioNet. Because ClaudicatioNet offers transparency of care with logistic support (referral packages, standardized feedback), ClaudicatioNet participation has evident advantages. Also, the mandatory key performance indicators of SET will help secure the collaboration of vascular surgeons and ClaudicatioNet in launching a regional network. As previously mentioned, SET is not recommended in the current guidelines of the Dutch General Practitioners Society and Dutch Society for Vascular Surgery. Given the evidence provided in the current literature, adjustment of these guidelines is urgently needed to ensure the best possible care for all patients with IC.

Another critical success factor is nationwide coverage. To achieve this goal, a sufficient number of PTs will need to participate. Given the number of referrals and the supply and demand dynamics in each regional network, the volume of patients will determine the economic trade-off for the individual PT. When a PT chooses not to participate in ClaudicatioNet, more referrals are divided among the remaining PTs. ClaudicatioNet will not actively interfere with the geographic distribution of participating PTs. In the near future, supply and demand of SET will evolve and eventually create a balance within the market. In a worstcase scenario, regional coverage may not be fully achieved in some areas. Should this situation arise, ClaudicatioNet will subsequently try to recruit PTs to those specific areas.

Monitoring, updating, and increasing the quality of ClaudicatioNet PTs will be a substantial task in the upcoming years and also an essential success factor. Participating PTs need to comply with a greater number of quality standards compared to nonparticipating PTs. It is necessary, in our opinion, to reward those PTs who provide excellent care according to the established quality standards. Compensation should be linear to the quality provided and, over time, health care insurers should compensate only the PTs who deliver excellent care standards. To accomplish this goal, health care insurers need to play a specific role in collaboration with ClaudicatioNet.

Another topic of discussion is financial compensation for patients. In our opinion, every patient admitted to ClaudicatioNet should be fully compensated for the conservative treatment program by the mandatory Dutch basic health care insurance. In the current Dutch health care system, patients who undergo a percutaneous vascular intervention or bypass surgery are fully compensated, in contrast to
SET, for which financial contribution by the patient is still compulsory. To advocate this, we will argue for a system in which superior care is fully compensated compared to less-superior care. It is our objective to convince the Health Care Insurance Board (CVZ) of this necessity.

Future research should assess if the ClaudicatioNet concept is an effective approach for critical limb ischemia patients who have undergone a percutaneous vascular intervention or peripheral bypass surgery. The initiation of a cost-effectiveness study of the ClaudicatioNet concept for treatment of IC will be the next step in determining the scope of efficiency.

\section{Conclusion}

In The Netherlands, evidence-based conservative treatment is not offered to all patients with IC. ClaudicatioNet was launched to improve the quality of care, access, continuity, and (cost) efficiency of the health care system. The chronic care model provides a conceptual framework of the structure and working method of ClaudicatioNet. With this care intervention, integrated care pathways should be improved in the upcoming years, resulting in optimal quality of care for all patients with IC.

\section{Acknowledgments}

The ClaudicatioNet Concept is supported by a grant from the Innovation Fund of the Joint Dutch Health Care Insurers Association.

The members of the ClaudicatioNet Study Group (in alphabetical order) include: ML Bartelink, BL Bendermacher, F Brooijmans, RA de Bie, HCW van Dalen, HJP Fokkenrood, HJH Gijsbers, L Gommans, HJM Hendriks, B Honing, S Kleinveld, LM Kruidenier, GJ Lauret, SP Nicolai, MH Prins, S Spronk, JAW Teijink, E Troe, N Verhofstad, S van de Voort, EM Willigendael.

\section{Disclosure}

The authors report no conflicts of interest in this work.

\section{References}

1. Norgren L, Hiatt WR, Dormandy JA, Nehler MR, Harris KA, Fowkes FG. Inter-Society Consensus for the Management of Peripheral Arterial Disease (TASC II). J Vasc Surg. 2007;45 Suppl S:S5-S67.

2. Fowkes FG, Housley E, Cawood EH, Macintyre CC, Ruckley CV, Prescott RJ. Edinburgh Artery Study: prevalence of asymptomatic and symptomatic peripheral arterial disease in the general population. Int $J$ Epidemiol. 1991;20:384-392.

3. Murabito JM, Evans JC, Nieto K, Larson MG, Levy D, Wilson PW. Prevalence and clinical correlates of peripheral arterial disease in the Framingham Offspring Study. Am Heart J. 2002;143:961-965. 
4. Hooij JD, Stoffers HE, Kester AD, Rinskens PE, Kaiser V. Risk factors and cardiovascular diseases associated with asymptomatic peripheral arterial occlusion disease. The Limburg PAOD Study. Scand J Prim Health Care. 1998;16:177-182.

5. Meijer WT, Hoes AW, Rutgers D, Bots ML, Hofman A, Grobbee DE. Peripheral arterial disease in the elderly: The Rotterdam Study. Arterioscler Thromb Vasc Biol. 1998;18:185-192.

6. Stoffers HE, Rinkens PE, Kester AD, Kaiser V, Knottnerus JA. The prevalence of asymptomatic and unrecognized peripheral arterial occlusive disease. Int J Epidemiol. 1996;25:282-290.

7. Leng GC, Lee AJ, Fowkes FG, et al. Incidence, natural history and cardiovascular events in symptomatic and asymptomatic peripheral arterial disease in the general population. Int J Epidemiol. 1996;25: 1172-1181.

8. Criqui MH. Systemic atherosclerosis risk and the mandate for intervention in atherosclerotic peripheral arterial disease. Am J Cardiol. 2001;88:43.J-47.J.

9. Hirsch AT, Haskal ZJ, Hertzer NR, et al. ACC/AHA 2005 Practice Guidelines for the management of patients with peripheral arterial disease (lower extremity, renal, mesenteric, and abdominal aortic): a collaborative report from the American Association for Vascular Surgery/Society for Vascular Surgery, Society for Cardiovascular Angiography and Interventions, Society for Vascular Medicine and Biology, Society of Interventional Radiology, and the ACC/AHA Task Force on Practice Guidelines (Writing Committee to Develop Guidelines for the Management of Patients With Peripheral Arterial Disease): endorsed by the American Association of Cardiovascular and Pulmonary Rehabilitation; National Heart, Lung, and Blood Institute; Society for Vascular Nursing; TransAtlantic Inter-Society Consensus; and Vascular Disease Foundation. Circulation. 2006;113:e463-e654.

10. Antithrombotic Trialists Collaboration. Collaborative meta-analysis of randomised trials of antiplatelet therapy for prevention of death, myocardial infarction, and stroke in high risk patients. $B M J$. 2002;324:71-86

11. Heart Protection Study Collaborative Group. Randomized trial of the effects of cholesterol-lowering with simvastatin on peripheral vascular and other major vascular outcomes in 20,536 people with peripheral arterial disease and other high-risk conditions. J Vasc Surg. 2007;45:645-654.

12. Stewart KJ, Hiatt WR, Regensteiner JG, Hirsch AT. Exercise training for claudication. N Engl J Med. 2002;347:1941-1951.

13. Erb W. About intermittent walking and nerve disturbances due to vascular disease. Dtsch Z Nervenheilkd. 1898;13:1-76.

14. Watson L, Ellis B, Leng GC. Exercise for intermittent claudication. Cochrane Database Syst Rev. 2008:CD000990.

15. Shephard RJ, Balady GJ. Exercise as cardiovascular therapy. Circulation. 1999;99:963-972.
16. Bartelink ML, Stoffers HE, Biesheuvel CJ, Hoes AW. Walking exercise in patients with intermittent claudication. Experience in routine clinical practice. Br J Gen Pract. 2004;54:196-200.

17. Bendermacher BL, Willigendael EM, Teijink JA, Prins MH. Supervised exercise therapy versus non-supervised exercise therapy for intermittent claudication. Cochrane Database Syst Rev. 2006:CD005263.

18. Kruidenier LM, Nicolai SP, Hendriks EJ, Bollen EC, Prins MH, Teijink JA. Supervised exercise therapy for intermittent claudication in daily practice. J Vasc Surg. 2009;49:363-370.

19. Dutch Institute for Healthcare Improvement $\mathrm{CBO}$ and Dutch College of General Practitioners. Consensus Cardiovasculair Risicomanagement [Dutch Guideline Cardiovascular Risk Management]. Utrecht, The Netherlands: Dutch Institute for Healthcare Improvement CBO; 2011.

20. Bartelink ML, Stoffers HEJH, Boutens EJ, Hooij JD, Kaiser V, Boomsma LJ. Guideline peripheral arterial disease from the Dutch General Practitioners Society. Huisarts Wet. 2003;46:848-858.

21. Vahl AC, Reekers JA. The guideline 'Diagnosis and treatment of peripheral artery disease of the lower extremities' of The Netherlands Surgical Society. Ned Tijdschr Geneeskd. 2005;149:1670-1674.

22. Lauret GJ, van Dalen HC, Hendriks HJ, et al. When is supervised exercise therapy considered useful in peripheral arterial occlusive disease? A nationwide survey among vascular surgeons. Eur J Vasc Endovasc Surg. 2012;43:308-312.

23. Jongert MW, Hendriks HJ, van Hoek J, Klaasboer-Kogelman K, Robeer GC, Simens B. KNGF-richtlijn Claudicatio Intermittens Guideline intermittent claudication from the Royal Dutch Society of Physical Therapy. Ned Tijdschr Fysioth. 2003;6:1-50.

24. Nicolai SP, Teijink JA, Prins MH. Multicenter randomized clinical trial of supervised exercise therapy with or without feedback versus walking advice for intermittent claudication. J Vasc Surg. 2010;52: $348-355$.

25. World Health Organization. Innovative Care for Chronic Conditions: Building Blocks for Action. Geneva, Switzerland: World Health Organization; 2002.

26. Zichtbare Zorg Ziekenhuizen. Indicator Set Chronic Peripheral Arterial Occlusive Diseases. The Hague, The Netherlands: Zichtbare Zorg Ziekenhuizen; 2011.

27. Epping-Jordan JE, Pruitt SD, Bengoa R, Wagner EH. Improving the quality of health care for chronic conditions. Qual Saf Health Care. 2004;13:299-305.

28. Miller WR, Rollnick S. Motivational Interviewing: Preparing People for Change. New York, NY: Guilford Press; 2002.

29. Rubak S, Sandbaek A, Lauritzen T, Christensen B. Motivational interviewing: a systematic review and meta-analysis. Br J Gen Pract. 2005;55:305-312.
Vascular Health and Risk Management

\section{Publish your work in this journal}

Vascular Health and Risk Management is an international, peerreviewed journal of therapeutics and risk management, focusing on concise rapid reporting of clinical studies on the processes involved in the maintenance of vascular health; the monitoring, prevention and treatment of vascular disease and its sequelae; and the involvement of

\section{Dovepress}

metabolic disorders, particularly diabetes. This journal is indexed on PubMed Central and MedLine. The manuscript management system is completely online and includes a very quick and fair peer-review system, which is all easy to use. Visit http://www.dovepress.com/ testimonials.php to read real quotes from published authors. 